\title{
FutureJournal
}

\section{Estudo do Impacto da Governança de Tecnologia da Informação no Desempenho das Empresas Brasileiras: uma Análise a partir da Perspectiva dos Executivos, Usuários e Membros de Equipes de TI}

\author{
Rogério Fernandes da Costa \\ Especialista em Gestão de Projetos pelo Centro Universitário de Santo André \\ rogerio.costa@fmu.br
}

\begin{abstract}
Alessandro Marco Rosini
Doutor em Comunicação e Semiótica pela Pontifícia Universidade Católica de São Paulo, PUC/SP, Brasil.

alessandro.rossini@hotmail.com
\end{abstract}

\section{RESUMO}

No presente trabalho, o objetivo principal é compreender como os modelos de melhores práticas de governança de Tecnologia da Informação (TI) podem impactar de forma positiva o desempenho das empresas brasileiras. Para este estudo quali-quantitativo, de nível exploratório descritivo, convidaram-se, por meio de um survey eletrônico, 38 empresas brasileiras que declararam utilizar modelos de melhores práticas de tecnologia da informação. A delimitação dos construtos ocorreu a partir da visão de executivos, usuários e membros de equipes de TI. Nos resultados, indica-se que existe uma tendência entre os executivos de relacionar diretamente a adoção de modelos de melhores práticas de governança de TI aos benefícios e custos estimados. No estudo, identificou-se também que, em ambientes onde os ativos humanos especializados são essenciais para a execução eficiente e eficaz de processos, satisfazer o contratante e os usuários de serviços de TI torna-se difícil. Nos resultados sugere-se ainda que 0 baixo envolvimento da alta gerência na identificação de melhoria nos processos internos da organização pode impactar negativamente a agilidade de entrega de resultados.

PALAVRAS-CHAVE: Governança corporativa. Planejamento estratégico. Governança de TI. 


\section{FutureJournal}

\section{Study Impact of Information Technology Governance in the Performance of Brazilian Business: an Analysis From the Perspective of Executives, Users and Members of it Teams}

\section{ABSTRACT}

This work is primarily aimed at understanding how the models of best practice in governance of Information Technology (IT) can positively impact the performance of Brazilian companies. This qualitative and quantitative study of exploratory and descriptive level was carried out through an electronic survey, to which were invited 38 Brazilian companies that reported using models of best information technology practices, the delimitation of the constructs is given from the perspective of executives, users and members of IT teams. The results indicate that there is a tendency among executives to relate directly the adoption of models of best IT governance practices to the estimated benefits and costs. The study also found that in environments where specialized human assets are essential to the efficient and effective implementation processes, meet the contractor and IT services users becomes difficult. The results suggest that the low involvement of top management in the improvement of identification in the internal processes of the organization can impact the results delivery agility negatively.

KEY-WORDS: Corporate governance. Strategic planning. IT governance. 


\section{INTRODUÇÃO}

Em virtude das constantes mudanças e exigências do mercado, o surgimento de novos modelos de gestão empresarial tem se acentuado nas últimas décadas. No contexto da governança, diferentes correntes de pensamento têm emergido ao longo dos anos procurando explicar e compreender as diferenças de desempenho entre empresas.

Diante da dinâmica complexa que envolve o planejamento estratégico, novas abordagens são construídas, como a teoria dos custos de transação (Coase, 1937; Williamson, 1985), a teoria da agência (Ross, 1973) e a visão da empresa baseada em recursos (Barney, 1991). Ao analisar-se a estrutura organizacional de uma empresa sob a ótica baseada em recursos, é preciso levar em consideração a possibilidade de criação de vantagem competitiva a partir de seu portfólio de recursos, sejam eles do tipo humano, organizacional, financeiro ou físico. Prahalad e Hamel (1990) ressaltam ainda que, para alcançar vantagens competitivas sustentáveis, as organizações precisam desenvolver competências essenciais (core competences).

No atual cenário, diversos fatores têm levado as organizações a reverem seus atuais modelos de gestão da tecnologia da informação (TI), entre eles: o maior grau de dependência do negócio em relação à área de TI; a complexidade cada vez maior dos recursos envolvidos; a necessidade de estar em conformidade com regulações definidas a partir de critérios de informação ou requisitos de negócio e a crescente demanda por transparência e prestação de contas. Esses fatores, aliados à necessidade de uso estratégico de tecnologia da informação, criaram condições propícias para o surgimento da governança de TI.

Em um ambiente empresarial marcado por hipercompetição e incertezas, a informação passa a ser um recurso fundamental para todas as organizações, sendo assim, identificar o grau de contribuição que a TI oferece para os resultados das empresas configura-se como um grande desafio para os gestores.

Neste estudo, o objetivo principal é compreender o potencial da governança de TI em contribuir com o desempenho das empresas 
brasileiras, a delimitação dos construtos ocorreu a partir da visão de executivos, usuários e membros de equipes de TI em empresas que declararam utilizar modelos de melhores práticas de tecnologia da informação. Os dados dessa pesquisa foram obtidos por meio de levantamento (survey), foi utilizado um questionário com perguntas padronizadas em escala do tipo Likert, enviado via e-mail. Participaram da pesquisa 29 profissionais representando 21 empresas.

Inicialmente neste artigo correlacionam-se os princípios da governança corporativa e da governança de TI, nesse ínterim, a partir de análise documental, o atual panorama da TI no país é apresentado. Em seguida, os procedimentos metodológicos são descritos. Na sequência, os resultados são apresentados e discutidos. Na seção final deste estudo, são apresentadas as considerações finais, os principais achados, limitações e direções para futuras pesquisas.

\section{GOVERNANÇA CORPORATIVA}

O tema governança corporativa surgiu na Inglaterra e nos Estados Unidos e vem sofrendo evolução ao longo dos anos. Inicialmente, a agenda sobre governança estava mais voltada a identificar falhas da governança, do que aos benefícios proporcionados pela adoção de boas práticas. Os primeiros códigos de melhores práticas de governança corporativa surgiram no início da década de 1990, mais precisamente em 1992. O primeiro livro cujo título continha a expressão governança corporativa foi publicado em 1995 (Bettarello, 2008).

Há uma relação histórica e direta envolvendo os escândalos ocorridos em 2002 e a posterior adoção de melhores instrumentos de governança corporativa. A observância dos fatos envolvendo os problemas ocorridos em grandes corporações internacionais como Enron, WorldCom e Parmalat, apontou fragilidades nas auditorias existentes nas relações entre proprietários, gestores e mercados. A gravidade desses fatos impactou de forma negativa o mercado financeiro, abalando a confiança dos investidores e aumentando a preocupação com a implementação de mecanismos de proteção aos stakeholders das empresas privadas (Weill \& Ross, 2006). 
Importante ressaltar que as questões envolvendo governança corporativa não se limitam à mera verificação de procedimentos contábeis ou de auditorias. De uma forma simplificada, o conceito de governança corporativa trata dos mecanismos ou princípios adotados no governo estratégico da empresa, articulando a distribuição de poder e o alinhamento de interesses entre as partes.

\subsection{CONFLITO DE AGÊNCIA}

O conceito de governança surgiu em decorrência da necessidade de separação entre a propriedade e a gestão empresarial; a partir desse ponto, é que começa a tornar-se mais evidente o conflito de agência. O problema de agência, também conhecido como problema agente-principal, consiste na dependência de maximização de valor da parte denominada principal (acionista) em virtude de decisões tomadas pelo agente (administrador). Embora o agente deva tomar decisões em benefício do principal, o conflito de interesses pode motivá-lo a tomar decisões em benefício próprio.

A grande contribuição teórica para essa temática ocorreu com o trabalho de Jensen e Meckling (1976). Em seus estudos, os autores definiram a teoria da agência como um contrato em que o principal delega autoridade de decisão ao agente para realizar trabalhos em seu favor. Contudo, estudos anteriores já haviam buscado correlacionar os interesses dos proprietários e o processo de remuneração dos administradores das empresas (Spence \& Zeckhauser, 1971; Ross, 1973), sendo, por isso, considerados por alguns autores como os primeiros trabalhos sobre a teoria da agência (Caixe, 2012; Silva Zonatto, Cordeiro \& Scarpin, 2012).

Ao analisar-se a crescente demanda por transparência no ambiente empresarial, deve-se levar em consideração duas premissas básicas: se de um lado, em ambientes nos quais ocorre o problema de agência, normalmente existe assimetria informacional (caracterizada quando, na ocorrência de uma transação, uma das partes detém mais informações do que a outra), por outro lado, a elevação dos níveis evidenciação abordando informações corporativas (disclosure) pode reduzir os custos de agência.

A qualidade das informações corporativas divulgadas contribui para minimizar riscos e incertezas, nesse contexto, os recursos de tecnologia da 
informação cumprem importante papel na governança corporativa. A adoção da tecnologia da informação envolvendo processos e transações comerciais contribui de forma direta para reduzir a assimetria informacional entre os diferentes agentes, provendo maior acesso às informações. Ao analisarem esses aspectos, Nascimento, Bianchi \& Terra (2008) afirmam:

Os sistemas de informação cumprem funções mais amplas do que o simples armazenamento de dados [...]. Os atributos dessa dimensão de controle a tornam uma peça-chave para a manutenção da segurança dos ativos da empresa para a explicação e divulgação de seus resultados econômicos a todos aqueles por ela interessados. Por essa razão, pode-se considerá-la uma das bases para o alcance das melhores práticas de governança corporativa e, se apropriadamente conservada, como um dos fatores que possibilitem a redução de conflitos entre principal e agente.

Segundo Batista (2004, p. 39), "[...] o objetivo de usar os sistemas de informação é a criação de um ambiente empresarial em que as informações sejam confiáveis e possam fluir na estrutura organizacional".

\section{GOVERNANÇA DE TI}

No âmbito dos modelos de gestão, a governança de TI surge como um instrumento fundamental para conduzir a gestão dos serviços de TI, pois, quando adotada de forma apropriada, pode ajudar a empresa a evitar riscos desnecessários. Tal justificativa apoia-se no fato de que a falta de supervisão da diretoria para atividades de TI, e de forma análoga a falta de auditoria em seus livros de demonstrações financeiras, pode expor a organização de maneira perigosa a riscos que poderiam ser evitados.

A responsabilidade da governança de TI é do conselho de administração e dos executivos, que consiste em lideranças e estruturas organizacionais, cuja principal finalidade é garantir a sustentação da empresa. Para isso, deve entender as estratégias, os objetivos e os processos da organização (ITGI, 2007). Assim, espera-se que, quanto melhor for a estrutura de governança corporativa, melhor serão as decisões tomadas pela administração, inclusive as relacionadas à governança de TI. Visão semelhante é compartilhada por Weill e Ross (2006, p. 8). Para os autores, a governança de TI é "a especificação dos direitos decisórios e do framework de responsabilidades para estimular comportamentos desejáveis na utilização da TI". 
Ao oferecer recomendações para o desenvolvimento de políticas de TI levando em consideração as necessidades operacionais e estratégicas da organização, a governança de TI pode contribuir de forma efetiva para melhorar sua performance e posição competitiva. Pesquisas apontam que empresas com bons modelos de governança de TI apresentam resultados superiores aos de suas concorrentes (Weill \& Ross, 2006).

Nos últimos anos, as discussões sobre investimentos e o papel da TI nas organizações brasileiras têm aumentado substancialmente, isso é perceptível em publicações tanto no âmbito acadêmico, como naquelas voltadas aos executivos e empresários, ou ainda, em publicações ou reportagens voltadas ao público em geral.

De acordo com dados da pesquisa Predictions Brazil 2014 Top Trends (IDC, 2014), o Brasil consolidou-se como o quarto maior mercado de TI e Telecom do mundo depois de Estados Unidos, China e Japão: a estimativa de investimentos em TI e Telecom no país até o final de 2014 é da ordem de US\$ 175 bilhões. Do ponto de vista estratégico, vale ressaltar que o simples fato de as empresas investirem em TI não lhes garante vantagem competitiva, é vital perceber a necessidade de quebra do paradigma vigente sobre o uso de tecnologia da informação apenas como ferramenta de suporte administrativo.

No processo de planejamento estratégico, os pressupostos motivacionais para investimentos devem considerar a significativa dependência entre os diversos setores e níveis hierárquicos da organização em relação aos serviços de TI. Nesse contexto, o conceito de governança de TI está atrelado às iniciativas que visam aumentar a qualidade e o controle dos serviços prestados pela TI para a empresa. Para Weill e Ross (2006), os recursos de TI envolvem todo e qualquer investimento que tem por finalidade gerar valor ao negócio a partir de recursos tecnológicos.

$\mathrm{Na}$ literatura, diferentes temáticas procuram relacionar o uso de TI a medidas de produtividade empresarial, contudo, ainda não existe um consenso sobre o papel ou os ganhos de produtividade proporcionados pelos investimentos em recursos de TI nas organizações. Se por um lado alguns autores tratam do chamado paradoxo da produtividade de TI (Strassman, 1990; Brynjolfsson, 1993; Gurovitz, 1997; Willcocks \& Lester, 1997), por outro, existem os que defendam a TI como um instrumento 
estratégico e agregador de valor (Cassarro, 1999; Frontini, 1999; Porter, 2001; Becker, Lunardi \& Maçada, 2003), na visão desses autores, a TI evoluiu de mera ferramenta de suporte administrativo para um papel estratégico na organização.

No que diz respeito aos ganhos estratégicos associados à utilização de TI, em 25 junho de 2015, a revista Executivos Financeiros publicou uma reportagem sobre uma instituição financeira que decidiu investir em uma solução para formalizar a entrada e a saída de funcionários da empresa, controlando, assim, o acesso ao sistema. A análise do estudo de caso mostra que a decisão pela adoção da solução foi acertada, pois, além de permitir a integração da folha de pagamento ao programa, a instituição conseguiu praticamente zerar a ineficiência de gestão de identidades, oferecendo garantias de que os processos internos e as transações bancárias fossem executados apenas por pessoas devidamente autorizadas. Neste caso em específico, pode-se observar que a obtenção de vantagem competitiva a partir do uso da TI pressupõe o alinhamento entre as estratégias de negócios e o uso da tecnologia da informação.

Leonard (1995) defende que a informação e a tecnologia, que a TI fornece para todos os setores, devem ser tratadas como ativos estratégicos pelas empresas comerciais e seus administradores. Embora as empresas administrem vários recursos, deve-se considerar a complexidade que envolve os recursos de TI utilizados pelo negócio a partir de quatro domínios fundamentais: estratégia empresarial, infraestrutura organizacional, estratégia de tecnologia da informação, e/ou processos.

Em face da complexidade das organizações e do atual ambiente empresarial, a obtenção de informações que favoreçam uma visão geral da empresa torna-se cada vez mais importante. Em um caso de sucesso relatado pela Microsoft, sem precisar de grandes investimentos, uma tradicional universidade do estado do Espírito Santo agilizou seus processos ao realizar a migração do seu ambiente de TI para a nuvem. Ao passar a suportar os picos de acesso aos sistemas e as necessidades sazonais, a instituição de ensino elevou seu nível de atendimento, proporcionando a percepção de aumento na qualidade dos serviços de TI prestados a professores e alunos. 
Ao proporcionar a rápida identificação de oportunidades de otimização no desempenho da organização e a consequente realização de ajustes para que os objetivos estratégicos sejam atingidos, a tecnologia da informação passa a ser imprescindível na atual gestão empresarial. Dessa forma, os recursos de TI passam a atuar como um catalisador no processo de tomada de decisão.

\subsection{MODELO DE GOVERNANÇA DE TI: COBIT}

Com a adoção de um modelo de governança, esperam-se garantias de que os gestores estarão exercendo corretamente seu papel. Independentemente do modelo de governança de TI adotado, por meio de medição, auditoria e acompanhamento dos contratos internos e externos, deve ser possível controlar a execução e a qualidade dos serviços de TI prestados à empresa. O Control Objectives for Information and Related Technology (COBIT) e o Information Technology Infrastructure Library (ITIL) são modelos de referência para governança de TI (Weill \& Ross, 2006).

O COBIT é um guia elaborado em 1994 pelo Information Systems Audit and Control Association (ISACA) para gestão e controle de processos de TI. A ISACA é uma organização global formada por profissionais de governança de TI, controle, segurança e auditoria. Esse guia utiliza um modelo (framework) que fornece as melhores práticas para o gerenciamento de processos e atividades de tecnologia da informação de forma estruturada, gerenciável e lógica. Importante frisar que a expressão melhores práticas adotada neste trabalho não significa necessariamente um procedimento padrão a ser seguido, de fato, nem sempre uma melhor prática representa a forma mais eficaz de fazer algo, por isso essas práticas evoluem e são atualizadas constantemente.

No atual cenário empresarial, o uso maciço da internet e a integração de aplicativos e tecnologia entre empresas tem se tornado uma prática recorrente no apoio aos processos de negócios, isso tem exigido das organizações o cumprimento de um crescente número de exigências legais e regulatórias. De forma genérica, o COBIT pressupõe que, para atender aos critérios de negócio de forma eficiente e eficaz, as informações devem 
estar em conformidade com regulações definidas a partir de critérios de informação ou requisitos de negócio, portanto, a política de informação deve ser adaptada de acordo com as necessidades da organização.

As partes interessadas exigem uma maior garantia de que as organizações estejam atuando conforme as leis e regulamentos e em conformidade com boas práticas de governança corporativa em seu ambiente de atuação. Além disso, devido ao fato de a TI ter permitido processos de negócios pervasivos integrados entre organizações, há ainda uma crescente necessidade de assegurar que os contratos incluam importantes requisitos de TI em áreas tais como privacidade, confidencialidade, propriedade intelectual e segurança. (ISACA, 2012, p. 63).

Além de incorporar padrões regulatórios internacionais, o COBIT, que atualmente se encontra em sua quinta versão, tem evoluído ao adicionar a seu arcabouço a contribuição de técnicos e profissionais com conhecimentos específicos. Como diferencial às demais versões, o COBIT 5 destaca a clara diferenciação entre as atividades de governança e gestão de TI.

A governança garante que as necessidades, condições e opções das partes interessadas sejam avaliadas a fim de determinar objetivos corporativos acordados e equilibrados; definindo a direção através de priorizações e tomadas de decisão; e monitorando o desempenho e a conformidade com a direção e os objetivos estabelecidos.

[...] A gestão é responsável pelo planejamento, desenvolvimento, execução e monitoramento das atividades em consonância com a direção definida pelo órgão de governança a fim de atingir os objetivos corporativos (ISACA, 2012, p. 16).

Nesse modelo, as interações entre os diferentes atores devem ser coordenadas e cooperadas. Enquanto a gestão da TI está focada na automatização e eficiência das operações e processos (contemplando a administração dessas operações e as decisões a serem tomadas acerca dos produtos e serviços de TI correspondentes), a governança de TI é mais ampla e foca a utilização da TI de maneira estratégica. Ao tomar decisões sobre redução de custos, otimização de recursos, benefícios e riscos, o sistema de governança deve considerar todas as partes interessadas.

Nesse ponto, alguns elementos merecem destaque. As partes interessadas podem ser influenciadas por necessidades distintas, como mudanças de estratégia, nível de satisfação dos usuários de negócio com os serviços de TI, mudanças nos negócios e no ambiente regulatório, bem como a necessidade de adoção de novas tecnologias. Outro ponto que 
merece destaque é que as seguintes perguntas devem ser feitas no processo de tomada de decisão: Quem toma as decisões? Como as decisões e resultados são monitorados? Para quem são os benefícios? Quem assume o risco? Que recursos são necessários?

\section{MÉTOdO E PROCEDIMENTOS DE PESQUISA}

Os dados analisados no presente artigo foram coletados no período de 30 de agosto a 15 de outubro de 2014; a coleta dos dados foi feita por questionário, aplicado como um survey eletrônico, com propósito exploratório-descritivo e de corte transversal (cross section). A pesquisa survey pode ser descrita como "a obtenção de dados ou informações sobre características, ações ou opiniões de determinado grupo de pessoas, indicado como representante de uma população-alvo, por meio de um instrumento de pesquisa, normalmente um questionário" (Freitas, Oliveira, Saccol \& Moscarola, 2000, p. 105).

Buscando favorecer o conhecimento nesse campo, foi adotada uma abordagem quali-quantitativa, a opção por essa metodologia mista justifica-se pela necessidade de estruturação do trabalho a partir da análise de conteúdo e da subsequente evidenciação dos dados observados de forma quantificada.

O instrumento de coleta de dados utilizado foi composto de questionário estruturado, dividido em três blocos, contendo:

- criação de valor da TI para o negócio: com seis questões de caracterização da empresa, contribuição da TI para o aumento dos lucros e diferentes mecanismos de relacionamento e geração de valor para a organização;

- capital intelectual e clima organizacional: com oito questões envolvendo pessoas, treinamento, comunicação interpessoal, qualificação e motivação dos membros das equipes de TI;

- mensuração do desempenho da TI: com cinco questões sobre processos, sistemas de controle, disponibilidade, cumprimento de prazos, qualidade e confiança nos serviços entregues pela TI.

Nos blocos foram adotadas questões do tipo Likert de cinco pontos que incluem as opções "concordo plenamente", "concordo parcialmente", 
"não tenho opinião formada", "discordo parcialmente" e "discordo totalmente".

O instrumento foi submetido a um pré-teste junto a dois especialistas: ambos são profissionais que possuem experiência consolidada na área de Tecnologia da Informação com expertise na implementação de modelos e mecanismos de governança de TI nas organizações. No primeiro bloco do questionário, procurou-se medir o grau de concordância (ou não) dos executivos de TI pesquisados quanto às diversas afirmações sobre o potencial benefício do uso de melhores práticas de governança de TI.

O segundo bloco do questionário foi respondido somente por usuários de serviços de TI em empresas que declararam utilizar modelos de melhores práticas de tecnologia da informação, as questões envolvem práticas implementadas e a percepção dos resultados obtidos. Neste bloco, para algumas afirmações associadas à percepção de importância da TI para execução dos processos, foi usada uma escala do tipo Likert, com as seguintes opções de resposta: "nenhuma importância", "pouca importância", "indiferente", "importante" e "extremamente importante".

No terceiro bloco do questionário, foram entrevistados membros da equipe de TI em empresas que declararam utilizar modelos de melhores práticas de tecnologia da informação; as questões contemplam o ambiente de trabalho, envolvimento da alta gerência na melhoria de processos e transparência na comunicação. Neste bloco, para algumas afirmações associadas ao nível de satisfação ao exercer as atividades, bem como à percepção de valorização profissional, foi usada uma escala do tipo Likert, com as seguintes opções de resposta: "piorou muito", "piorou", "não mudou", "melhorou pouco" e "melhorou". Durante a implantação ou mudança de uma tecnologia, é importante mostrar, sistematicamente, os motivos e as vantagens, de forma que os membros da equipe de TI possam vir a colaborar com o projeto. Buscando identificar a eficácia dos canais de comunicação utilizados no processo decisório, foi adotada uma escala de transparência estabelecida conforme o nível de atendimento dos critérios predefinidos, variando de 0 (nenhum critério foi atendido) a 100 (atendimento pleno):

- 0 a 20 - nada transparente;

- 21 a 40 - pouco transparente; 
- 41 a 60 - transparência satisfatória;

- 61 a 80 - transparente;

- 81 a 100 - totalmente transparente.

No Quadro 1, é exibido um breve resumo da metodologia empregada neste estudo.

\begin{tabular}{|c|c|c|c|}
\hline \multicolumn{2}{|c|}{ Caracterização da Pesquisa } & \multicolumn{2}{|c|}{ Organização da Pesquisa } \\
\hline $\begin{array}{l}\text { Abordagem } \\
\text { Metodológica }\end{array}$ & Quali-quantitativa & $\begin{array}{l}\text { Objeto } \\
\text { Empírico }\end{array}$ & $\begin{array}{c}38 \text { empresas que } \\
\text { declaram utilizar } \\
\text { melhores práticas de TI }\end{array}$ \\
\hline $\begin{array}{l}\text { Tipo de } \\
\text { Pesquisa }\end{array}$ & $\begin{array}{l}\text { Exploratória } \\
\text { descritiva }\end{array}$ & $\begin{array}{l}\text { Quantidade de } \\
\text { Observações }\end{array}$ & $\begin{array}{l}29 \text { questionários } \\
\text { válidos (representando } \\
21 \text { empresas) }\end{array}$ \\
\hline $\begin{array}{l}\text { Técnica de } \\
\text { Investigação }\end{array}$ & Survey & $\begin{array}{l}\text { Unidade de } \\
\text { Análise }\end{array}$ & Organizacional \\
\hline $\begin{array}{l}\text { Instrumento } \\
\text { de Coleta }\end{array}$ & Questionário & $\begin{array}{l}\text { Unidade de } \\
\text { Observação }\end{array}$ & $\begin{array}{l}\text { CIOs, gerentes, } \\
\text { usuários e membros de } \\
\text { equipes de TI }\end{array}$ \\
\hline $\begin{array}{l}\text { Análise dos } \\
\text { Dados }\end{array}$ & $\begin{array}{l}\text { Estatística } \\
\text { descritiva }\end{array}$ & $\begin{array}{l}\text { Enfoque de } \\
\text { Observação }\end{array}$ & $\begin{array}{c}\text { Governança de TI e } \\
\text { alinhamento } \\
\text { estratégico. }\end{array}$ \\
\hline $\begin{array}{l}\text { Perspectiva } \\
\text { Temporal }\end{array}$ & $\begin{array}{c}\text { Corte transversal: } \\
\text { um dado momento } \\
\text { no tempo }\end{array}$ & $\begin{array}{c}\text { Critério de } \\
\text { Seleção da } \\
\text { Amostra }\end{array}$ & $\begin{array}{c}\text { Conveniência (por } \\
\text { adesão) }\end{array}$ \\
\hline
\end{tabular}

Quadro 1: Metodologia empregada no trabalho

Escolheu-se como população empresas que declaram utilizar melhores práticas de TI em grupos da rede social LinkedIn, a partir do compartilhamento de informações envolvendo o nome da empresa, cargo e e-mail, executivos, usuários e membros de equipes de TI foram convidados a acessar o site em que estava disponibilizada a pesquisa e a participar dela. De um total de 38 empresas convidadas, 21 aceitaram o convite e preencheram o questionário on-line. A situação das 38 empresas após as etapas de contato inicial e envio do convite é apresentada no Quadro 2.

\begin{tabular}{|l|l|}
\hline Situação da empresa & Quantidade \\
\hline Aceitou participar & 21 \\
\hline Não aceitou participar & 2 \\
\hline Não deu retorno & 15 \\
\hline Total & 38 \\
\hline
\end{tabular}

Quadro 2: Contato inicial e confirmação de interesse 


\section{APRESENTAÇÃO E DISCUSSÃO DOS RESULTADOS}

A amostra aqui analisada é do tipo não probabilística por conveniência, visto que os participantes foram escolhidos a fim de que se pudesse ter acesso às repostas da pesquisa. Das 38 empresas que declaram adotar melhores práticas de governança de TI convidadas a participar da pesquisa, 21 aceitaram, obtendo-se, desse modo, uma fração significativa para a análise, $55 \%$ da população.

A partir das informações fornecidas sobre as características das empresas, o perfil dos respondentes contatados na pesquisa está dividido basicamente em seis segmentos. O setor mais representativo da população é o de serviços, com 60\%, seguido do setor educacional, com 20\% e das áreas de saúde, finanças, teledifusão e associação esportiva com $5 \%$ cada uma. Das 21 empresas pesquisadas, 60\% possuem mais de 500 funcionários; 30\%, entre 50 e 249 funcionários; e os 10\% restantes da amostra são compostos por empresas que possuem entre 20 e 49 funcionários.

Os dados aqui analisados foram levantados no intuito de relacionar as características das empresas estudadas com os benefícios do uso de melhores práticas de governança de $\mathrm{TI}$, principalmente no que diz respeito à percepção de geração de valor ao negócio. A amostra compõe-se de 29 questionários válidos que foram respondidos por executivos, usuários e membros de equipes de TI. Em apenas três empresas (14,3\%), o

\begin{tabular}{|l|l|l|l|}
\hline Perfil & $\mathbf{n}$ & $\mathbf{\%}$ & $\mathbf{\%}$ Acumulado \\
\hline Executivos & 12 & $41,4 \%$ & $41,4 \%$ \\
\hline Membros de equipes & 10 & $34,5 \%$ & $75,9 \%$ \\
\hline Usuários & 7 & $24,1 \%$ & $100 \%$ \\
\hline Total & $\mathbf{2 9}$ & $\mathbf{1 0 0} \%$ & $\mathbf{1 0 0} \%$ \\
\hline
\end{tabular}

questionário foi respondido por um representante de cada perfil; em duas empresas somente dois participantes de perfis diferentes preencheram o questionário $(9,5 \%)$; na maioria dos casos (16 empresas, 76,2\%) apenas um participante respondeu ao questionário em nome da empresa. A distribuição dos respondentes de acordo com seu perfil é apresentada no Quadro 3. 


\section{Quadro 3: Perfil dos participantes}

No tocante à análise quantitativa dos dados, em sua totalidade, os executivos respondentes posicionaram-se de forma positiva com relação à importância das melhores práticas de TI para o aumento do controle e da qualidade dos serviços prestados pela TI aos diversos setores da empresa. Do total de respostas válidas, $83,33 \%$ concordam plenamente e outros $16,67 \%$ concordam parcialmente com essa afirmativa. Da mesma forma, $83,33 \%$ dos participantes concordam plenamente que a adoção de modelos de melhores práticas de TI influencia o aumento da agilidade e da confiabilidade na realização de processos empresariais. Já 16,67\% concordam parcialmente com essa afirmação.

Com $100 \%$ de respostas positivas, o maior grau de dependência do negócio em relação à área de TI foi considerado pelos executivos como um fator determinante para as empresas adotarem modelos de governança de TI $(66,67 \%$ dos respondentes concordaram plenamente e os $33,33 \%$ restantes concordaram com a afirmação sobre a questão).

Com relação à opinião dos executivos sobre a contribuição das melhores práticas de governança de TI para o aumento dos lucros da empresa, $50 \%$ dos respondentes concordam plenamente e 41,67\% concordam parcialmente com essa afirmativa, o que resulta em um total de $91,67 \%$ de concordância. Não houve respostas negativas com relação a essa questão, apenas $8,33 \%$ dos respondentes indicaram não ter opinião formada a respeito.

No que diz respeito aos diferentes mecanismos de relacionamento e geração de valor para a organização, 58,33\% dos executivos afirmam que os membros da equipe de TI se submeteram a treinamento interfuncional entre TI e negócios nos últimos 12 meses; de acordo com 16,66\% dos executivos respondentes, nos últimos 12 meses, conselho administrativo, gerentes funcionais e departamentais passaram por treinamento formal em governança de TI; e em 25\% dos casos, nos últimos 12 meses, nenhum nível hierárquico recebeu treinamento. Questionados sobre a existência de um programa formal visando às certificações ITIL/COBIT, embora 16,67\% dos executivos tenham respondido que não exista e que não tenham a intenção de desenvolver esse programa, na expressiva maioria dos casos 
$(83,33 \%)$, os executivos afirmaram que, apesar de não existir o programa, têm a intenção de desenvolvê-lo.

Da análise dos dados qualitativos, percebe-se a existência de uma tendência entre os executivos de relacionar diretamente a adoção de modelos de melhores práticas de governança de TI aos benefícios e custos estimados, porém, mesmo diante da consciência da importância da governança de TI para geração de valor do negócio, as iniciativas voltadas ao treinamento e à qualificação interfuncional dos colaboradores demonstraram-se bastante tímidas.

Embora as empresas administrem vários recursos, a maturidade na governança corporativa e dos principais ativos de TI varia de forma significativa nas principais organizações. Convém lembrar que não basta à empresa ter as melhores ferramentas, no monitoramento efetivo, devem considerar-se três aspectos em conjunto: pessoas, processos e tecnologias. Neste sentido, a falta de atualização dos conhecimentos dos colaboradores sobre processos de gerenciamento, técnicas, procedimentos e decisões ligadas à TI pode expor a empresa a riscos desnecessários. Para assegurar que a TI proporcione valor ao negócio, as organizações precisam desenvolver competências essenciais que permitam fazer comparações e balancear o uso de recursos limitados (Farbey, Land \& Targett, 1992). Ressalta-se que os resultados apresentados são decorrentes de fatos que foram descritos, mas não observados, por isso, é possível que os executivos tenham reportado um nível de maturidade que eles gostariam de ter ou estão prestes a alcançar, em contraposição ao que já alcançaram. Uma validação empírica seria necessária para verificar a veracidade dessa hipótese.

No segundo bloco de questões, buscou-se identificar a percepção dos membros das equipes de TI sobre temas envolvendo capital intelectual e clima organizacional das empresas pesquisadas. Do total de respostas válidas fornecidas, $50 \%$ dos respondentes declararam que a empresa onde trabalham possui mecanismos de governança de TI implementados há mais de cinco anos, já entre um e três anos foi o período declarado por $30 \%$ dos respondentes, e outros $20 \%$ declararam entre três e cinco anos.

Questionados sobre como classificariam o envolvimento da alta gerência na tentativa de melhorar os processos internos da organização, 
$60 \%$ dos respondentes classificaram a alta gerência como pouco ativa; $30 \%$, como ativa; e os outros $10 \%$, como muito ativa.

No que diz respeito às mudanças de tecnologia, os membros das equipes de TI foram convidados a avaliar o grau de transparência no processo decisório da alta gerência para com eles. Do total de respostas válidas, 50\% dos respondentes consideraram o grau de transparência no processo decisório como satisfatório; na opinião de $40 \%$ dos respondentes o processo decisório é transparente; e 10\% avaliaram esse processo como pouco transparente. Se por um lado não houve registros de nenhuma resposta afirmando que o processo decisório não é nada transparente, tampouco houve registros sobre o processo decisório ser totalmente transparente.

Questionados sobre a exigência das certificações ITIL/COBIT para os membros da equipe de TI e/ou gerentes de projetos, do total de respondentes, 60\% afirmaram que, embora sejam vistas como um diferencial, as certificações não são exigidas; $20 \%$ afirmaram que as certificações não são exigidas, perfazendo um total de $80 \%$ de percepções negativas a esse respeito. Contudo, um número significativo de respondentes (20\%) afirma que as certificações ITIL e/ou COBIT são prérequisitos nas organizações onde trabalham.

Entre os benefícios proporcionados pela adoção de mecanismos de governança de TI, a oportunidade de crescimento profissional é apontada pelos membros de equipes de TI como um dos principais ganhos no ambiente de trabalho. Dos respondentes, 50\% afirmaram que a oportunidade de crescimento profissional melhorou, para $30 \%$ dos respondentes houve pouca melhora, somando um total de $80 \%$ de percepções positivas a esse respeito. Entretanto, uma parcela significativa dos respondentes discorda dessa afirmativa. Para $20 \%$ dos respondentes, não houve mudança nesse quadro. Ressalta-se que, apesar de haver opiniões bastante divergentes, não houve registro de nenhum caso de declínio nesse aspecto.

Ao serem questionados sobre o nível de satisfação ao exercer as atividades profissionais após a adoção de mecanismos de governança de TI, não houve divergências nas respostas entre os membros de equipes de TI. 
$80 \%$ dos participantes afirmam que seu nível de satisfação melhorou e outros $20 \%$ admitem pouca melhora no seu nível de satisfação.

É importante destacar que a capacidade de inovação e respostas à mudança no ambiente de TI depende em grande parte da rotina de trabalho de suas equipes. Sendo assim, a renovação dos processos de trabalho está diretamente ligada à capacidade da empresa em gerar competências organizacionais a partir das competências individuais. Outro ponto a considerar é que o envolvimento, a transparência, a responsabilidade e a integração dos colaboradores e da alta gerência são fatores de sucesso para o correto mapeamento, desenho e alinhamento de processos.

No terceiro bloco formado por questões que se referem ao desempenho da TI, do total dos sete questionários válidos representando os usuários de serviços de TI, ainda que não tenha havido respostas sobre declínio na qualidade dos serviços, enquanto $42,86 \%$ dos respondentes declararam que a qualidade dos serviços de TI melhorou após a adoção de mecanismos de governança, para outros $57,14 \%$ a qualidade melhorou pouco.

Questionados sobre a importância da cultura empresarial e dos sistemas de controle e monitoramento no auxílio à execução dos processos de negócio, 71,43\% dos respondentes consideram importante; 14,29\%, extremamente importante; e 14,29\%, pouco importante. Não houve registro de usuários de serviços de TI que considerem essa questão sem nenhuma importância.

Com relação à melhoria no cumprimento de prazos, levando-se em consideração o antes e o após da adoção de mecanismos de governança de $\mathrm{TI}, 74,43 \%$ dos respondentes afirmaram que houve pouca melhora nesse quadro, enquanto para outros $28,57 \%$ melhorou.

Questionados sobre o nível de confiança nos serviços entregues pela TI após a adoção de mecanismos de governança de TI, 42,86\% dos respondentes declararam que melhorou pouco; para 42,86\% melhorou; e outros $14,29 \%$ declararam que nada mudou.

Com relação à opinião dos usuários de TI sobre a importância de treinamento, experiência, julgamento e inteligência dos membros da equipe de TI para execução eficiente e eficaz de processos rotineiros da empresa, 
do total de respondentes, $71,43 \%$ consideram esses fatores extremamente importantes e $28,57 \%$ classificaram-nos como importantes.

As respostas oferecidas pelos usuários de serviços de TI demonstraram que, embora a expressiva maioria dos respondentes declare que a cultura empresarial e os sistemas de controle e monitoramento contribuam para a execução dos processos de negócio, nem todos têm a percepção dos ganhos proporcionados pela adoção de mecanismos de governança de TI. Segundo Dutra (1996), no entanto, quando percebe que os resultados desejados estão sendo alcançados, o indivíduo fica mais satisfeito consigo e com suas atividades, e essa satisfação é transferida para o seu trabalho.

Ademais, as informações sobre os níveis de satisfação dos usuários consistem em importante indicador para as empresas comprometidas com a qualidade dos serviços de TI, contribuindo com a melhoria contínua de seus processos e, por conseguinte,com a satisfação de seus clientes, sejam eles internos ou externos.

\section{CONSIDERAÇÕES FINAIS}

Em virtude de a área de negócio estar cada vez mais dependente das tecnologias da informação (TI), o uso estratégico desses recursos se faz necessário e, para que atenda a todos os níveis da organização, são necessárias ações integradas, uma vez que, ao se concentrarem na esfera tática da organização, as ações ficam limitadas à solução de problemas imediatos e de pouca abrangência.

Dessa forma, os resultados do estudo mostraram que os índices referentes ao envolvimento da alta gerência na tentativa de melhorar os processos internos da organização, em sua maioria, estão aquém dos índices esperados pelo mercado. Infere-se que esse achado pode estar relacionado ao fato da pouca melhora no cumprimento de prazos percebido pelos usuários de serviços de TI.

Em outra análise, verificou-se ainda que as variáveis treinamento e comunicação interpessoal que não foram bem avaliadas, apresentaram correlação com o grau de satisfação dos usuários de serviços e membros de equipes de TI no que se refere à qualidade dos serviços e aos níveis de 
transparência. Portanto, é provável que, se houver incremento no treinamento entre setores e, além disso, elevação do nível de transparência no processo decisório, ocorra um impacto de forma positiva no desempenho da organização, elevando, assim, seus níveis de serviço e, consequentemente, a satisfação dos diferentes stakeholders, que pertencem a essa organização. Vale salientar que o fator treinamento foi um dos itens que apresentaram maior número de correlações significativas com os construtos avaliados.

Como limitações desta pesquisa, destacam-se a natureza do estudo, o tamanho da amostra e a taxa de retorno (cerca de 55\%). Devido ao tamanho reduzido da amostra, não é possível a generalização dos resultados, limitando-os às 21 empresas analisadas. Outra limitação importante refere-se à operacionalização da variável percepção de geração de valor ao negócio, cabe salientar que, em apenas três das 21 empresas que participaram da pesquisa survey, representantes dos três perfis distintos responderam à pesquisa; na expressiva maioria dos casos (16 empresas, 76,2\%), apenas um participante de cada perfil respondeu ao questionário em nome da empresa.

Por fim, um aspecto positivo deste estudo reside no fato de que os resultados obtidos ao longo da pesquisa levam ao entendimento de que os ativos humanos configuram-se entre os mais carentes de governança. Assim, em ambientes onde os ativos humanos especializados são essenciais para a execução eficiente e eficaz de processos, satisfazer o contratante e os usuários de serviços em relação à performance, é algo difícil de ser alcançado.

Tais constatações apontam para a necessidade de desenvolvimento de um estudo futuro com uma amostra de maiores dimensões. O aprofundamento em futuras investigações pode contribuir para elucidar como os pontos relacionados ao baixo grau de transparência no processo decisório de implantação ou mudança de tecnologia pode impactar a agilidade de entrega de resultados em times de alta performance. 


\section{REFERÊNCIAS}

Bancos investem em gestão de identidades. Executivos Financeiros. Recuperado em: 12 de novembro, 2015, de http://www.executivosfinanceiros.com.br/ti/seguranca/item/1000bancos-investem-em-gest\%C3\%A3o-de-identidades.html

Barney, J. (1991). Firm resources and sustained competitive advantage. Journal of management, 17(1), 99-120.

Batista, E. (2004) Sistemas de informação o uso consciente de tecnologia para o gerenciamento. São Paulo: Saraiva.

Becker, J. L., Lunardi, G. L., \& Maçada, A. C. G. (2003). Análise de eficiência dos bancos brasileiros: um enfoque nos investimentos realizados em tecnologia de informação (TI). Revista Produção, 13(2), 70-81.

Bettarello, F. C. (2008). Governança corporativa: fundamentos jurídicos e regulação. São Paulo: Quartier Latin.

Brynjolfsson, E. (1993). The productivity paradox of information technology. Communications of the ACM, 36(12), 66-77.

Caixe, D. F. (2012). Relação dinâmica entre a estrutura de propriedade e controle e o valor de mercado corporativo no Brasil: análise da primeira década do século XXI. Dissertação de Mestrado, Faculdade de Economia, Administração e Contabilidade de Ribeirão Preto, SP, Brasil.

Cassarro, A. C. (1989). Sistemas de informações para tomada de decisões (3a ed.). São Paulo: Pioneira.

Coase, R. H. (1937). The nature of the firm. Economica, 4(16), 386-405.

Dutra, J. S. (1996). Administração de carreiras. São Paulo: Atlas.

Farbey, B., Land, F., \& Targett, D. (1992). Evaluating investments in IT. Journal of Information Technology, 7(2), 109-122.

Freitas, H., Oliveira, M., Saccol, A. Z., \& Moscarola, J. (2000). O método de pesquisa survey. Revista de Administração da Universidade de São Paulo - Rausp, 35(3), 105-112.

Frontini, B. F. (1999). A decision making model for investing in electronic business Doctoral Dissertation, Massachusetts Institute of Technology, Sloan School of Management, Management of Technology Program, USA.

Gurovitz, H. (1997). Delete-se. Revista Exame, ano 30, n.12, ed. 637, p. 86-95.

Instituto Brasileiro de Governança Corporativa - IBGC. (2009) Código das melhores práticas de governança corporativa (4a ed.). São Paulo: IBGC. 
International Data Corporation - IDC (2014) Predictions Brazil 2014 TOP Trends. Recuperado em 15 de novembro, 2014, de http://www.brasscom.org.br/brasscom/Portugues/download.php?cod=56 7

ISACA (2012). COBIT 5 Modelo corporativo para governança e gestão de TI da organização. Recuperado em 20 de novembro, 2014, de http://www.isaca.org/COBIT/Pages/COBIT-5-Portuguese.aspx

IT Governance Institute - ITGI. (2007). Board briefing on IT Governance (2nd ed.). Rolling Meadows, IL: IT Governance Institute.

Jensen, M. C., \& Meckling, W. H. (1976). Theory of the firm: Managerial behavior, agency costs and ownership structure. Journal of Financial Economics, 3(4), 305-360.

Leonard, D. (1995). Wellspring of knowledge: building and sustaining the sources of innovation. Boston: Harvard Business School Press.

Microsoft. Caso de sucesso Universidade de Vila Velha. Recuperado em 12 de novembro, 2015, de http://www.microsoft.com/ptbr/case/details.aspx?Id $=1196$

Nascimento, A. M., Bianchi, M., \& Terra, P. R. S. (2006). A controladoria como um mecanismo interno de governança corporativa: evidência de uma survey comparativa entre empresas de capital brasileiro e norteamericano. Anais do Encontro Nacional da Associação de Pós-Graduação e Pesquisa em Administração - EnAnpad, 29, Salvador, BA, Brasil.

Porter, M. E. (2001). Strategy and the Internet. Harvard Business Review, 79(3), 62-79.

Prahalad, C. K., \& Hamel, G. (1990). The core competence of the corporation. In N. Foss (Ed.), Resources, firms, and strategies: a reader in the resource-based perspective (1st ed., pp. 235-256). Oxford, UK: Oxford University Press.

Silva Zonatto, V. C. da, Cordeiro, A., \& Scarpin, J. E. (2012, May). Práticas de gestão de custos em uma instituição de ensino superior: uma análise à luz da teoria da agência. Proceedings of the CONTECSI - International Conference on Information Systems and Technology Management, 9, São Paulo, SP, Brasil.

Ross, S. A. (1973). The economic theory of agency: The principal's problem. The American Economic Review, 63(2), 134-139.

Spence, M., \& Zeckhauser, R. (1971). Insurance, information, and individual action. The American Economic Review, 61(2), 380-387.

Strassmann, P. A. (1990). The business value of computers: an executive's guide. New Canaan, CT: Information Economics Press. 
Weill, P., \& Ross, J. W. (2006). Governança de tecnologia da informação: como as empresas com melhor desempenho administram dos direitos decisórios de TI na busca por resultados superiores. São Paulo: Makron.

Willcocks, L. P., \& Lester, S. (1997). In search of information technology productivity: assessment issues. Journal of the Operational Research Society, 48(11), 1082-1094.

Williamson, O. E. (1985). The economic institutions of capitalism. Firms, markets, relational contracting. New York: The Free Press. 